\title{
High performance liquid chromatography method for the detection of released purinergic and biogenic amine signalling molecules from in vitro ileum tissue
}

\author{
Ayemon Lwin ${ }^{1}$ and Bhavik Anil Patel ${ }^{1,2 *}$ \\ ${ }^{1}$ Department of Bioengineering, Imperial College London, London, SW7 2AZ \\ ${ }^{2}$ Centre for Biomedical and Health Sciences Research, University of Brighton, \\ Brighton, BN2 4GJ \\ *Address for correspondence: Bhavik Anil Patel, School of Pharmacy and \\ Biomolecular Sciences, University of Brighton, Brighton, BN2 4GJ, Tel.: +44 \\ (0)1273 641912, Fax: +44 (0)1273 679333, Email: b.a.patel@ brighton.ac.uk
}

Keywords: adenosine tri-phosphate, nucleotides, serotonin, ileum, microbore HPLC.

\begin{abstract}
Adenosine triphosphate (ATP) and serotonin (5-HT) are known to play key roles in the function and activity of the gastrointestinal tract; however no methods have been established for monitoring of these signalling molecules within one assay. We have developed a simple chromatographic methodology using UV/visible detection for the analysis of purinergic and biogenic amine signalling molecules. The chromatographic separation was achieved in an isocratic mode, where the mobile phase consisted of $5 \%$ methanol and $95 \%$ ammonium phosphate buffer with $10 \mathrm{mM}$ tetrabutylammonium bisulfate. Column temperature of $45{ }^{\circ} \mathrm{C}$ provided the means to separate all analytes within 14.7 minutes. Good resolution and tailing factors were observed for all components within the separation. The limit of detection for ATP and 5-HT was $30 \mathrm{nM}$ and $317 \mathrm{nM}$ respectively with a linear range from $10-0.02 \mu \mathrm{M}$. In vitro measurements were carried out by using aliquots from buffer the tissue was stored in after 30 mins to measure released molecules. In vitro assay of ileum tissue in the presence and absence of endogenous ATP was carried out. Results showed that ATP can elevate 5-HT release. This method can be used study alterations in these key signalling molecules with gastrointestinal disease.
\end{abstract}




\section{INTRODUCTION}

Adenosine triphosphate (ATP) is a well known as an important molecule responsible for a degree of biological functions such as metabolism, influencing vascular tone and also acting as a neurotransmitter [1-5]. In the gastrointestinal tract, ATP has been shown to play a key role as a signalling molecule that influences serotonin $(5-\mathrm{HT})$ release, which is well known to influence intestinal motility. ATP is believed to be present in epithelial cells located in the mucosal wall of the intestinal tract. ATP is released following mechanical stimulation of the mucosal wall and has been indicated to mediate 5-HT release from enterochromaffin (EC) cells [6-7]. However at present there are no methods developed for the measurement of ATP and serotonin within one assay, which would be important to understand the role of ATP on 5-HT. Alterations in 5-HT transmission have been observed in patients suffering from gastrointestinal disorders such as ulcerative colitis [8-11]. As ATP is believed to have a direct influence on 5-HT release, detection of these two signalling molecules will provide a means of understanding the relationship of these two signalling molecules and how they alter during gastrointestinal disorders.

There are limited methodologies that allow for the simultaneous measurements of 5HT and ATP; however chromatographic methods can achieve this. At present temporal detection of 5-HT release from EC cells have been established using borondoped diamond and carbon fibre microelectrodes, where $\mu \mathrm{M}$ levels of released transmitter were detected [12-15]. A chromatographic method for the detection of 5HT and metabolites from gastrointestinal tissue has also been developed [16]; however no methods have been established for the detection of ATP from gastrointestinal tissue to date.

Many chromatographic methods have been developed for measurements of biogenic amines and purinergic signalling molecules, however no methods have been established which allow for the simultaneous measurement of both these important transmitters within one assay. For the detection of biogenic amines, such as 5-HT, chromatographic separation is best conducted with an electrochemical detector [1621], however Ultra violet / visible (UV/Vis) and fluorometric detection have also been utilised [22-24]. Many chromatographic methods exist which provide excellent sensitivity with detection limits in the femtomolar range. Separations have also been achieved for analysis of multiple biogenic amines and catecholamine's within 10 minutes, allowing for rapid measurement [17,20,21]. Such developed methods have 
been successfully applied to study many significant biological applications [16,1921,25-27]. However as ATP is not electroactive within a short potential range, UV/Vis detectors have been predominately used in previous methodologies [28-30]. A variety of methods exist for the detection of ATP and metabolites, where both gradient and isocratic approaches have been utilised. Retention times from such assays vary from 9.2 mins to 18.7 mins [28-30].

Within this study we have established a simple chromatographic method for the detection of purinergic and biogenic amine neurotransmitters. We have created a method for the analysis of 5-HT, ATP and their metabolites as well as known transmitter interferences within the gastrointestinal system. Measurements were carried out from ileum tissue samples following optimisation of the chromatographic method where released levels of these signalling molecules were monitored in the presence and absence of endogenous ATP.

\section{EXPERIMENTAL}

\subsection{Chemicals}

3,4 dihydroxyphenethylamine (Dopamine), 5-hydroxytryptamine (serotonin, 5-HT), adenosine-5'-monophosphate (AMP), tryptophan, 3,4-dihydroxyphnylacetic acid (DOPAC), adenosine-5'-diphosphate (ADP), 5-hydroxy-3-indoleacetic acid (5-HIAA), adenosine-5'-triphosphate disodium salt (ATP), ammonium phosphate monobasic, tetrabutylammonium bisulphate were obtained from Sigma Aldrich and used as received.

All other chemicals were obtained from Sigma and used as received. All solutions were prepared in class A volumetric glassware.

\subsection{Sample preparation}

All animal experiments were carried out in compliance with the relevant laws and institution guidelines. Male guinea-pigs weighing 300-400 g were euthanized using $\mathrm{CO}_{2}$ gas. For HPLC, segments of ileum were removed and stored in oxygenated $(95 \%$ $\mathrm{O}_{2}$ and $5 \% \mathrm{CO}_{2}$ ) Krebs buffer solution, $\mathrm{pH}$ 7.4, (composition in $\mathrm{mM} ; 117 \mathrm{NaCl}, 4.7$ $\mathrm{KCl}, 2.5 \mathrm{CaCl} 2,1.2 \mathrm{MgCl} 2,1.2 \mathrm{NaH} 2 \mathrm{PO} 4,25 \mathrm{NaHCO} 3$ and 11 glucose) prior to sample preparation. 
A $1 \mathrm{~cm}$ long segment of ileum was transferred to a well containing Krebs buffer within a modified tissue well plate. This modified tissue culture plate consisted of a 16 well plate, of which the bottom of each well was lined with $5 \mathrm{~mm}$ thickness of Slygard 184 silicone elastromer (Dow Corning, USA) to provide a surface for pinning down the tissue. The tissue sample was then cut open along the mesenteric border and pinned down flat on the modified tissue well plate. Once the tissue section was pinned down, it was washed two times using Krebs buffer to remove any waste or excised mucus during tissue transfer. Following this the tissue was then kept in $1.5 \mathrm{ml}$ of Krebs buffer. After 30 mins, $250 \mu 1$ of this buffer was taken and passed through a 0.2 $\mu \mathrm{m}$ syringe filter and injected for analysis, to provide a measure of released neurotransmitters.

\subsection{Chromatography}

The HPLC system consisted of HP1050 autosampler equipped with a $5 \mu$ loop, column heater kept constantly at $45 \pm 0.15{ }^{\circ} \mathrm{C}$, a quaternary pump and UV/Vis detector (Agilent, USA). LUNA ${ }^{\circledR} 5 \mu \mathrm{m} 150$ x $1.0 \mathrm{~mm}$ i.d. analytical column with 4.0 x $2.0 \mathrm{~mm} 5 \mu \mathrm{m}$ guard column (Phenomenex ${ }^{\circledR}$, Macclesfield, UK) was utilised. The HPLC system was used in an isocratic mode for the determination of neurotransmitters. The HPLC system was run with a $100 \mu 1 \mathrm{~min}^{-1}$ flow rate, and an injected sample volume of $5 \mu \mathrm{l}$ was used. BAS ChromGraph ${ }^{\mathrm{TM}}$ software was used for control and data collection/processing. The HP1050 UV detector was set at a wavelength of $260 \mathrm{~nm}$ based upon characterisation studies.

The mobile phase composition was based upon optimisation and modifications from previous work [29-31] for the detection of ATP. The stock buffer for the mobile phase was composed of $0.1 \mathrm{M}$ ammonium phosphate monobasic and $10 \mathrm{mM}$ tetrabutylammonium (TBA) bisulfate dissolved in $1 \mathrm{~L}$ of deionised, distilled water and buffered to $\mathrm{pH} 7.46$ using $2 \mathrm{M}$ sodium hydroxide. To prepare the mobile phase, the ammonium phosphate buffer ( $\mathrm{pH}$ 7.46) was mixed with methanol (LC-MS CHROMASOLV ${ }^{\circledR}$ for HPLC) in the ratio 95.0:5.0 (v/v) and degassed after mixing.

\subsection{Standards and Calibration}

Standard solutions were prepared from a $500 \mu \mathrm{M}$ stock standard of each analyte prepared in the mobile phase buffer. Each of the standard solutions were prepared on 
the day of analysis and stored at $4{ }^{\circ} \mathrm{C}$ between injections. A calibration range was obtained by running individually a range of concentrations of 5-HIAA, tryptophan, 5HT, dopamine, DOPAC, AMP, ADP and ATP through the developed chromatographic method. Concentrations investigated ranged from 0.01 to $10 \mu \mathrm{M}$.

\subsection{Data analysis and interpretation}

As the tissue samples were isolated and stored within a fixed volume of buffer, which was utilised for analysis, normal methods to normalise chromatographic responses to the sample such as per weight or protein content $[16,28,32,33]$ do not pose a true representation of the experiments conducted within this study. Normalisation methods such as protein content or per weight are good markers for intracellular levels in which normally tissues are homogenised. In our case the tissue was kept intact in suitable conditions to record extracellular levels of released signalling molecules, we have normalised the chromatographic responses obtained by tissue area. The tissue area was calculated by a pixel counting algorithm which has been widely used [34-36]. Photographic images were taken of the modified tissue well plate in which the tissue samples were placed and the image was processed using IMAGE $\mathbf{J}$ software [37] to accurately measure the area of the pinned out isolated ileum tissue sections in pixel numbers, which was converted to $\mathrm{cm}^{2}$. The concentrations of the signalling molecules from the chromatographic assay (obtained from calibration curves of the analytes) was then normalised to the area of the tissue.

\section{RESULTS AND DISSCUSSION}

\subsection{Suitable detection wavelength for detection of all neurotransmitters}

Figure 1 shows the UV/Vis sepctras from the neurochemicals of interest from a range spreading from 380 to $220 \mathrm{~nm}$. However for all the signalling molecules the maximum absorbance is observed at various wavelengths. However the main focus of this study was to monitor extracellular levels of ATP and breakdown products and thus the focus was based around the wavelength where AMP, ADP and ATP provided the maximum absorbance. All 3 of the compounds have the same wavelength at 260 $\mathrm{nm}$ for maximum absorbance. ATP as expected had the greatest absorbance. Other transmitters such as 5-HT and dopamine had a maximum response around $270 \mathrm{~nm}$, but there was sufficient absorbance of these molecules at $260 \mathrm{~nm}$. These biogenic 
amines and catecholamines also have a shoulder on the absorbance peak. This is felt to be due to the peaks responsible for unpaired and ion-paired compounds. The wavelength of $260 \mathrm{~nm}$ was therefore utilized for the UV detector. The chosen wavelength was the same in other HPLC methods used to measure ATP using UV detection $[29,31]$.

\subsection{Influence of TBA concentration on retention time}

Knowing that ATP is deprotonated at $\mathrm{pH}$ 7.5, the suitable concentration of ion-pairing agent was investigated. Previously for ATP measurements, high concentration of triethylamine (TEA; $100 \mathrm{mM}$ ) was utilised as the ion pairing reagent [31]. As this ionpairing agent only has three ethyl chains, thus a limited interaction with the stationary phase is observed providing shorter retention times and therefore higher concentration of the ion-pairing agent is required for efficient separation. Although the use of TEA can provide the ability to obtain faster separations, it also can act to limit the scope for obtaining excellent resolution of the purinergic transmitters from biogenic amines and catecholamines.

Therefore tetrabutylammonium phosphate (TBA) was utilised in our study as it provides more interaction with the column and also provided a wider separation window. In Figure 2 the influence of retention time on the concentration of the ionpairing agent is shown. In the absence of TBA within the mobile phase, the separation between the 8 samples was not well resolved even though the largest molecule ATP came out in less than 20 minutes. When the concentration of TBA was increased up to $20 \mathrm{mM}$, the separation between the components became well resolved with increasing retention time of each analyte. Retention time for ATP, the final component to elute, was 27.2 minutes. As the concentration of TBA increased from $20 \mathrm{mM}$, all the components began to overlap as they eluted at similar times. This was most likely due to the extensive adsorption of excess TBA on the C18 column, causing an alteration in the behaviour of the stationary phase. With the column behaving as essentially a TBA phase, the retention time of ATP decreased. ATP will have a limited interaction with the TBA compared to the interaction of the $\mathrm{C} 18$ phase. The resolution was greater than 1.5 between all the components when $10 \mathrm{mM}$ TBA was utilized within the mobile phase for the detection of these analytes. Although the resolution was greater for a concentration of $20 \mathrm{mM} \mathrm{TBA}$, the separation at an excellent resolution was faster when utilising $10 \mathrm{mM}$ TBA. All components were eluted within 23.9 minutes. 
TBA has also been utilised in another study of adenine nucleotides, where the ionpairing agent offered more efficient in retention and separation of the adenosine molecules than TEA [29]. They also showed that smaller amounts of TBA was also required than TEA.

\subsection{Chromatography}

Figure 3 shows the results from the chromatographic analysis, where an isocratic mode was utilised to obtain complete separation of the neurotransmitters. This response shows that it can be possible to separate out not just only purinergic signalling molecules, but also other classical neurotransmitters within the same assay. This is essential to understand the link between 5-HT and ATP. There are no previous studies that have looked into monitoring these two types of transmitter molecule within one assay. However surprisingly there are assays that require the use of a gradient mode solely for the separation of ATP and breakdown products $[28,30]$. When gradient assays were carried out retention times greater than 20 minutes were achieved for the elution of ATP.

We have like other methods utilised the percent of the organic solvent in the mobile phase to enhance our separation as shown in Figure 3A. However we have further improved the retention time of the solutes by elevating the temperature as shown in Figure 3B. For optimal separation $5 \%$ methanol was utilised and a column temperature of $45^{\circ} \mathrm{C}$. All separations were obtained with a capacity factor of less than 6 (retention time of approximately 14.7 minutes).

The separation of all eight components is shown in Figure 3C. Retention times of dopamine, 5-HT, AMP, tryptophan, DOPAC, ADP, 5-HIAA and ATP were 2.21, 2.71, $4.18,6.53,7.52,8.48,9.95$ and 14.7 minutes respectively. The number of theoretical plates $(N)$ was 908, 890, 937, 2546, 1528, 2002, 2636 and 1240 for dopamine, 5-HT, AMP, tryptophan, DOPAC, ADP, 5-HIAA and ATP respectively. Minimal peak tailing was observed for all components (tailing factors in the range of 0.8 to 1.0) except for ATP, where the tailing factor was 3.45. There was also good resolution $(R s)$ observed between all the components. Adequate resolution was observed between dopamine and 5-HT; tryptophan and DOPAC, where values of Rs were 0.4 and 0.68 respectively. Good resolution ( $R s$ values around 1) was observed for nearly all other components except for the separation of 5-HIAA with ATP and AMP with tryptophan, where excellent resolution was observed $(R s>1.5)$. 
During repeated runs $(n=15)$ of the eight analytes a shift of $\pm 5 \%$ in the retention time was observed, which was accepted as a tolerance level for the assay. Chromatographs were deemed to be accepted if the tailing factor did not exceed 1.2 for any analyte and the resolution for separation between 5-HT and AMP dropped below 0.8.

Using a mobile phase consisting of $5 \%$ methanol and $95 \%$ ammonium phosphate buffer with $10 \mathrm{mM}$ tetrabutylammonium bisulfate and a column temperature of $45{ }^{\circ} \mathrm{C}$ it was possible to separate all of the major analytes within 15 minutes. This short multi-analyte analysis time for neurochemicals provides an ideal basis for biological tissue samples. In other chromatographic methods, retention times of ATP were observed between 9.2 to 18.7 minutes [28-31]. For the detection of 5-HT, dopamine and other small molecule transmitters a wide range of methods exist in either gradient and isocratic mode with retention times varying from 10 to 30 minutes $[17,18,21,25$ 27]. Our method achieved separation of all neurochemicals within 15 minutes, but this method is able to measure both purinergic and biogenic amine neurotransmitters within one assay.

The ability to measure dopamine and DOPAC within the same assay is also of great benefit as these signalling molecules are not present within the enteric nervous system but are common interferences. These molecules play a key role in the sympathetic nerves that innervate the gastrointestinal tissue $[38,39]$.

\subsection{Linearity and detection limits}

For each analyte a calibration curve was obtained in two working ranges. This was conducted to account for the range of metabolites and precursor molecules that are present in varying concentrations within the gastrointestinal tract. Table 1 shows the calibration range of the analyte of choice, the limit of detection (LOD, based on the 3 standard deviations of the $\mathrm{y}$ intercept using least-squares regression) and the correlation coefficient $\left(R^{2}\right)$. These calibration curves allow for the detection of ATP, serotonin, metabolites and interferences from tissue samples.

The limits of detection are $85 \mathrm{nM}$ for 5-HIAA, $82 \mathrm{nM}$ for tryptophan, $317 \mathrm{nM}$ for 5HT, $40 \mathrm{nM}$ for AMP, $23 \mathrm{nM}$ for ADP, $30 \mathrm{nM}$ for ATP, $172 \mathrm{nM}$ for dopamine and 182 $\mathrm{nM}$ for DOPAC. While these LOD values are relatively low for all cases, other papers have reported greater sensitivity when utilising electrochemical detection $[18,40]$. This is especially the case for biogenic amines where femtomoles of transmitter have been detected [40]. However these LOD values are fit for our purpose for 
measurements from gastrointestinal tissue where the levels of neurotransmitters are much greater than other biological areas. No measurements have been conducted to study released gastrointestinal ATP levels, however 5-HT levels have been widely studied. Using both electrochemical sensors and HPLC, extracellular and intracellular levels of 5-HT were in the $\mu \mathrm{M}$ range [14-16]. These levels are expected as ninety percent of the bodies' 5-HT content is present within enterochromaffin cells which are located within the mucosa lining of the gastrointestinal tract $[41,42]$.

\subsection{Influence of stabilisation time on extracellular levels of transmitters}

As extracellular levels were measured, the time required to observe stable responses of release was investigated. Once the tissue is isolated and kept within physiological buffer, the tissue will require recovery time before normal activity is resumed. In figure $4 \mathrm{~A}$, responses of the components observed released from ileum tissue and the response of the Krebs buffer is shown after 10 minutes. The background response from Krebs buffer shows a negative peak which interferes with the peak of 5-HT. Therefore for all responses the background signal was subtracted from the tissue response. Only responses for serotonin and AMP were observed from tissue samples. No peaks were observed for ATP, ADP and 5-HIAA. As AMP is detected, which is a breakdown product of ATP, this suggests ATP is present. However this doesn't confirm that ATP is released. ATP is broken down by membrane located ecto-ATPase enzyme to ADP and then AMP. As extracellular levels of the signalling molecules were monitored, 5-HIAA was not observed as expected, as this metabolite is formed following reuptake of 5-HT into the presynaptic cell after being release.

When looking at the influence of stabilisation time, as shown in figure $4 \mathrm{~B}$, there is no significant difference in the levels of 5-HT released between 30 and 60 minutes. The 5-HT response gradually increases following removal and isolation of the tissue to stabilise at around 30 minutes. Therefore 30 minutes stabilisation time was chosen as a suitable time frame for obtaining accurate measures of tissue response in physiological buffer.

In figure $4 \mathrm{C}$, the response of the tissue following analysis after 2 hours is shown. Responses are now observed for ATP, ADP, AMP, 5-HIAA and 5-HT. These components are as expected to be released from the tissue, except for 5-HIAA. Baseline resolution of all of the components was observed in the separation. ATP is observed in the separation, indicating that it is released from the mucosa into the 
lumen. As higher levels of AMP and also ADP are observed, the released ATP is broken down by mucosal located ecto-ATPase enzyme at a high rate. In this response a clear ATP peak is seen after 2 hours, however during the first hour following tissue isolation, an ATP response was not observed. This is felt to be due to reduced activity of the ecto-ATPase enzyme as conditions for the in vitro measurement are not suitable for the continued efficient activity of the enzyme. The loss in activity is due to that fact that the tissue sample is not continually perfused with new nutrients. Therefore measurement carried out after 30 minutes stabilisation times are appropriate and AMP can be utilised as a marker of ATP release.

5-HIAA is also observed after 2 hours, which is usually an intracellular marker for clearance of 5-HT. As 5-HIAA is observed in the extracellular matrix, it is removed by some process from the tissue. This removal may be due to the accumulation of high levels and thus removal provides a means of total clearance from the system. An additional peak was also observed (retention time of $6.1 \mathrm{mins}$ ) which is shown in figure $4 \mathrm{C}$, which was not characterised from the components analysed. This peak may be due to intestinal peptides released from the mucosa, such as vasoactive intestinal peptide (VIP) or substance P $[43,44]$ or due to phosphorylated transmitters.

\subsection{In vitro ileum tissue responses}

To understand the role of ATP on serotonin, measurements were carried out using the developed method to study the amount of 5-HT released in the presence and absence of endogenous ATP. Figure 5A shows a chromatograph of ileum tissue, where control measurements are compared to that where the tissue is placed in $5 \mu \mathrm{M}$ ATP. From responses in Krebs buffer alone only responses of AMP and 5-HT release was observed following 30 minutes stabilisation time. No response for ATP was observed indicating the efficiency of the ecto-ATPase enzyme activity. In figure 5B and C response of serotonin and AMP are shown between control responses and those when spiked with ATP. During control measurements from ileum tissue the amount of 5-HT and AMP observed was $4.59 \pm 0.59 \mu \mathrm{M} \mathrm{cm}^{-1}$ and $162.0 \pm 44.1 \mathrm{nM} \mathrm{cm}^{-1}(n=9)$ respectively. When ileum tissue was spiked with $5 \mu \mathrm{M}$ ATP, levels of 5-HT and AMP were $6.53 \pm 1.23 \mu \mathrm{M} \mathrm{cm}^{-1}$ and $799.7 \pm 150.1 \mathrm{nM} \mathrm{cm}^{-1}(n=7)$ respectively. There is a significant increase $(p<0.01, t$-test) in the amount of 5-HT released from ileum tissue when spiked with ATP (Figure 5B). This suggest that ATP is increasing release of 5- 
HT and may act as the key signalling molecule that elevates 5-HT release following mechanical stimulation [6,7].

There is a significant increase $(p<0.001, t$-test) in levels of AMP when the tissue is spiked with ATP (Figure 5C), suggesting that the enzyme ecto-ATPase is effectively breaking down ATP to form AMP. This is further supported by the fact that the ATP peak observed from tissue responses accounts for only $19.1 \%$ of the ATP standard added ( $p<0.01, n=7$, Figure 5D) and that also ADP is observed. An additional peak at 7.7 mins is also observed when endogenous ATP is added, which may be a released intestinal peptide.

Previously studies using electrophysiology and also using a model EC cell line has been utilised to suggest that intestinal ATP elevates 5-HT release. This is the first direct study to show that ATP elevates 5-HT release using isolated ileum tissue sections. As 5-HT has been indentified as a key molecule to regulate motility in the gastrointestinal tract, ATP may be a more important target to study in relationship to 5-HT, as it can regulate its release. This is of importance as 5-HT levels are known to alter during gastrointestinal diseases [9,10] and development [32] and thus ATP levels could account for such alterations.

\section{CONCLUSIONS}

We have established a simple method for the simultaneous detection of 5-HT, ATP and by-products. An isocratic chromatographic method was developed where separation of the eight components were achieved within 15 minutes. Good resolution was observed between all components with minimal peak tailing. Uv/Vis detection was utilised for measuring the components at a wavelength of $260 \mathrm{~nm}$. The developed method was able to detect released signalling molecules from isolated ileum tissue. Following endogenous application of ATP, 5-HT levels increased from ileum tissue. The developed method allows for a means of understanding the role of mechanical stimulation on the signalling process of these two transmitters in the digestive tract and can provide a means of understanding changes in signalling molecules during gastrointestinal disorders.

\section{ACKNOWLEGEMENTS}

BAP acknowledges support provided by an EPSRC LSI postdoctoral research fellowship grant (EP/C532058/1) and BBRSC grant (BB/G015147/1). 


\subsection{REFERENCES}

1. Hamilton, S. G, McMahon, S.B., J. Auton. Nerv. Syst. 2000, 81, 187 - 194.

2. Schwiebert, E. M., Zsembery, A., Biochim. Biophys. Acta 2003, 1615, 7 - 32.

3. Deitmer, J.W., Respir. Physiol. 2001, 129, 71 - 81.

4. Dale, N., J. Physiol. 2008, 586, 2429 - 2436.

5. Fields, R.D., Burnstock, G., Nat. Rev. Neurosci. 2006, 7, 423-436

6. Cooke, H.J., Wunderlich, J., Christofi, F.L., News Physiol. Sci. 2003, 18, 43 49.

7. Bertrand, P.P., Neuroscientist 2003, 9, $243-260$.

8. Gershon, M.D., Tack, J., Gastroenterology 2007, 132, 397 - 414.

9. Coates, M.D., Mahoney, C.R, Linden, D.R., Sampson, J.E., Chen, J., Blaszyk, H., Crowell, M.D., Sharkey, K.A., Gershon, M.D., Mawe, G.M., and Moses, P.L., Gastroenterology 2004, 126, 1657 - 1664.

10. Linden, D.R., Chen, J.-X., Gershon, M.D., Sharkey, K.A., Mawe, G.M., Am. J. Physiol. Gastrointest. Liver Physiol. 2003, 285, G207 - G216.

11. Galligan, J.J., Gastroenterology 2004, 126, 1897 - 1899.

12. Bertrand, P.P., Neurogastroenterol. Motil. 2004, 16, 511 - 514.

13. Bertrand, P.P., J. Physiol. 2006, 577, $689-704$.

14. Patel, B.A., Bian, X., Quaiserova-Mocko, V., Galligan, J.J., Swain, G.M., Analyst 2007, 132, $41-47$.

15. Patel, B.A., Analyst 2008, 133, 516 - 524.

16. Chau, R.M.W., Patel, B.A., Biomed. Chrom. 2009, 23, 175 - 181.

17. Saller, C.F., Salama, A.I., J. Chrom. Biomed. Appl. 1984, 309, 287 - 298.

18. Cheng, F.-C., Kuo, J.-S., J. Chrom. B 1995, 665, 1 - 13.

19. Durkin, T.A., Caliguri, E.J., Mefford, I.N., Lake, D.M., Macdonald, I.A., Sundstrom, E., Jonsson, G., Life Sciences 1985, 37, 1803 - 1810.

20. De Vries, M., J. Odink, J., J. Chrom. Biomed. Appl. 1991, 564, 250 - 257.

21. Patel, B.A., Arundell, M., Parker, K.H., Yeoman, M.S., O'Hare, D., J. Chrom. B $2005,818,269-276$.

22. Bearcroft, C.P., M. J. G. Farthing, M.J.G., Perret, D., Biomed. Chrom. 1995, 9, $23-27$. 
23. Fujino, K., Yoshitake, T., Kehr, J., Nohta, H., Yamaguchi, M., J. Chrom. A 2003, 1012, $169-177$.

24. Kai, M., Iida, H., Nohta, H., Lee, M.K., Ohta, K., J. Chrom. B 1998, 720, 25 31.

25. Mayer, G.S., Shoup, R.E., J. Chrom. 1983, 255, 533 - 544.

26. Barber, A., Kempter, B., Comparative Biochem. Physiol. C 1986, 84, 171 - 174.

27. B. H. C. Westerink, J. Chrom. B (2000) 747, 21 - 32.

28. Manfredi, G., Yang, L., Gajewski C.D., Mattiazzi, M., Methods 2002, 26, 317 326.

29. Sudo, J.-i., Terui, J., Iwase, H., Kakuno, K., J. Chrom. B 2000, 744, 19 - 23.

30. Tetens, J., Barker, S., Waguespack, M., Hosgood, G., Can. J. Vet. Res. 2001, 65, $133-135$.

31. Uesugi, T., Sano, K., Uesawa, Y., Ikegami, Y., Mohri, K., J. Chrom. B Biomed. Sci. Appl. 1997, 703, $63-74$.

32. Bian, X., Patel, B., Dai, X., Galligan, J.J., Swain, G., Gastroenterology (2007) 132, $2438-2447$.

33. Villanacci, V., Bassotti, G., Nascimbeni, R., Antonelli, E., Cadei, M., Fisogni, S., Salerni, B., Geboes, K., Neurogastroenterol. Motil. 2008, 20, 1009 - 1016.

34. Devanne, H., Cassim, F., Ethier, C., Brizzi, L., Thevenon, A., Capaday, C., European J. Neurosci. 2006, 23, 2467 - 2476.

35. B. G. Clark, J. L. Robar, and M.P. Petric, Med. Phys. (2006) 33, 96 - 105.

36. Chubb, C., Inagaki, Y., Sheu, P., Cummings, B., Wasserman, A., Head, E., Cotman, C., Neurobiol. Aging, 2006, 27, 1462 - 1476.

37. McAtee, P.S., Robert, P.S., Johnston, J., Hallett, I., Plant methods (2009) 5, 5

38. Park, J., Quaiserova-Mocko, V., Peckova, K., Galligan, J.J., Fink, G.D., Swain, G.M., Diamond Rel. Mat. 2006, 15, $761-772$

39. Park, J., Galligan, J.J., Fink, G.D., Swain, G.M., J. Physiol. 2007, 584, 819 834.

40. Thorre, K. Pravda, M., Sarre, S., Ebinger, G., Michotte, Y., J. Chromatogr. B: Biomed. Sci. Appl. 1997, 694, 297- 303.

41. Raybould, H.E., Cooke, H.J., Christofi, F.L., Neurogastroenterol. Motil. 2004, $16,60-63$.

42. Gershon, M.D., Aliment. Pharmacol. Therapeutics 1999, 13, 15 - 30. 
43. Arimura, A., Culler, M.D., Matsumoto, K., Kanda, M., Itoh, Z., Murphy, W., Shively, J.E., Palkovits, M., Peptides 1984 5, 41 - 44.

44. Makhlouf, G.M., Murthy, K.S., Cellular Signalling 1997, 9, 269 - 276. 


\section{FIGURE LEGENDS}

FIGURE 1. Uv / Vis spectra responses for all analytes to obtain a suitable detection wavelength. Measurements were made using the mobile phase as the control to the analyte sample.

FIGURE 2. Influence of retention time on the concentration of tetrabutylammonium. Responses were carried out at $100 \mu \mathrm{min}^{-1}$ flow rate using $5 \%$ acetonitrile, $95 \%$ ammonium phosphate buffer with a column temperature of $20^{\circ} \mathrm{C}$.

FIGURE 3. Chromatographic method parameters. (A) shows the influence of increasing methanol content on retention time, where the column temperature is $20{ }^{\circ} \mathrm{C}$, (B) shows the effect of temperature on the separation, where mobile phase with $5 \%$ methanol content is used and (C) shows a chromatogram of standard mixture present in mobile phase at $100 \mu \mathrm{min}^{-1}$ flow rate using $5 \%$ acetonitrile, $95 \%$ buffer with 10 $\mathrm{mM}$ tetrabutylammonium sulfate at $50{ }^{\circ} \mathrm{C}$ column temperature. Solutes: 1 , dopamine; 2, serotonin; 3, AMP; 4, DOPAC; 5, tryptophan; 6, ADP; 7, 5-HIAA and 8, ATP.

FIGURE 4. Effect of stabilisation time on released transmitters from biological tissue. (A) shows response from the ileum tissue with comparison to a control sample of buffer, in (B) the influence of stabilisation time on the amount of 5-HT observed is plotted and in (C) the released transmitter from an ileum sample after 2 hours is shown, where all components are observed. From the biological measurements, 500 $\mu \mathrm{l}$ of the tissue stabilisation buffer was utilised for injection.

FIGURE 5. Influence of ATP on 5-HT release from ileum tissue. In (A) chromatograph of released analytes observed from ileum in the presence and absence of endogenous ATP, in (B) and (C) the concentration of 5-HT and AMP observed from the tissue during control and when spiked experiments are shown respectively. (D) shows the amount of spiked ATP broken down to by the tissue. All conditions similar to that in figure 3. (Mean \pm St.Dev., $n=7$ to 9 , ** $p<0.01$, *** $p<0.001$ ) 
TABLE 1. Calibration range, limit of detection, $R^{2}$ values from a linear regression analysis of the peak area for the standards $(n=3)$. Each of the standards is individually analysed. All conditions similar to that in figure 3 . 
FIGURE 1

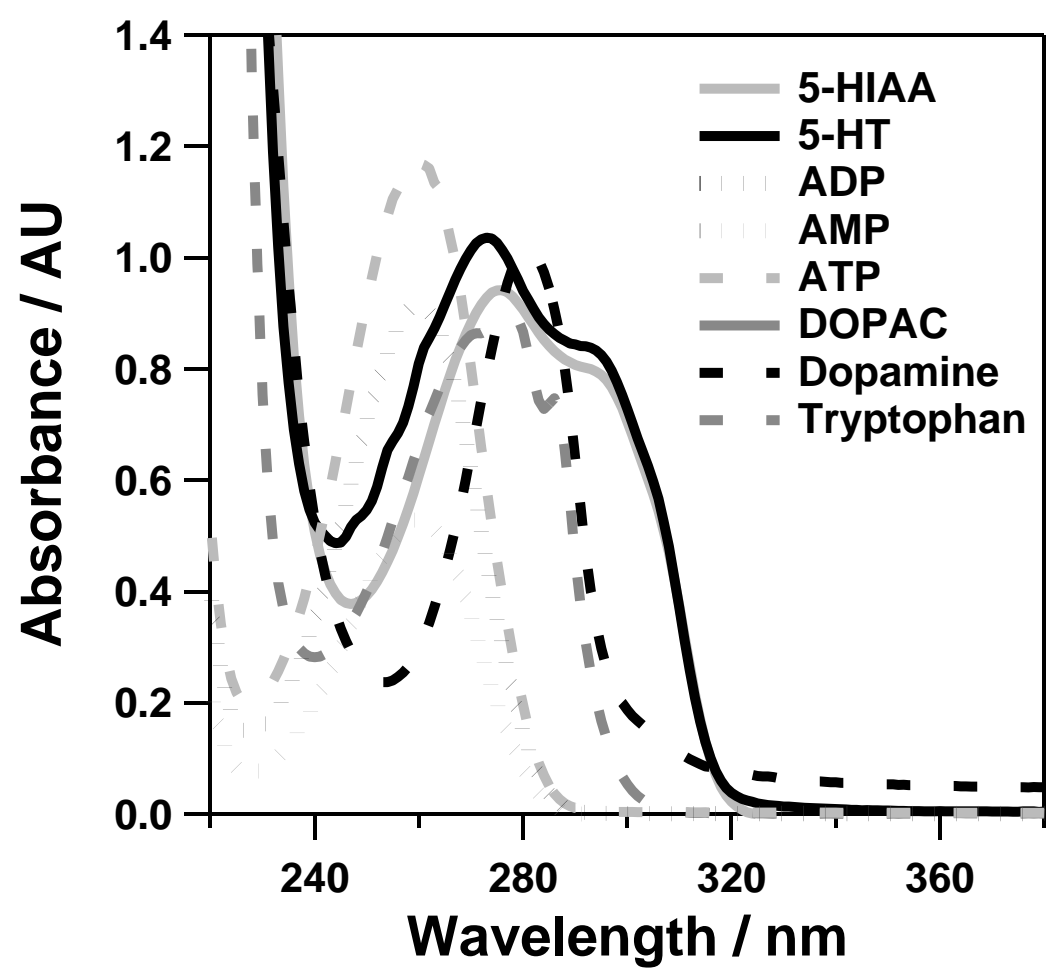


FIGURE 2

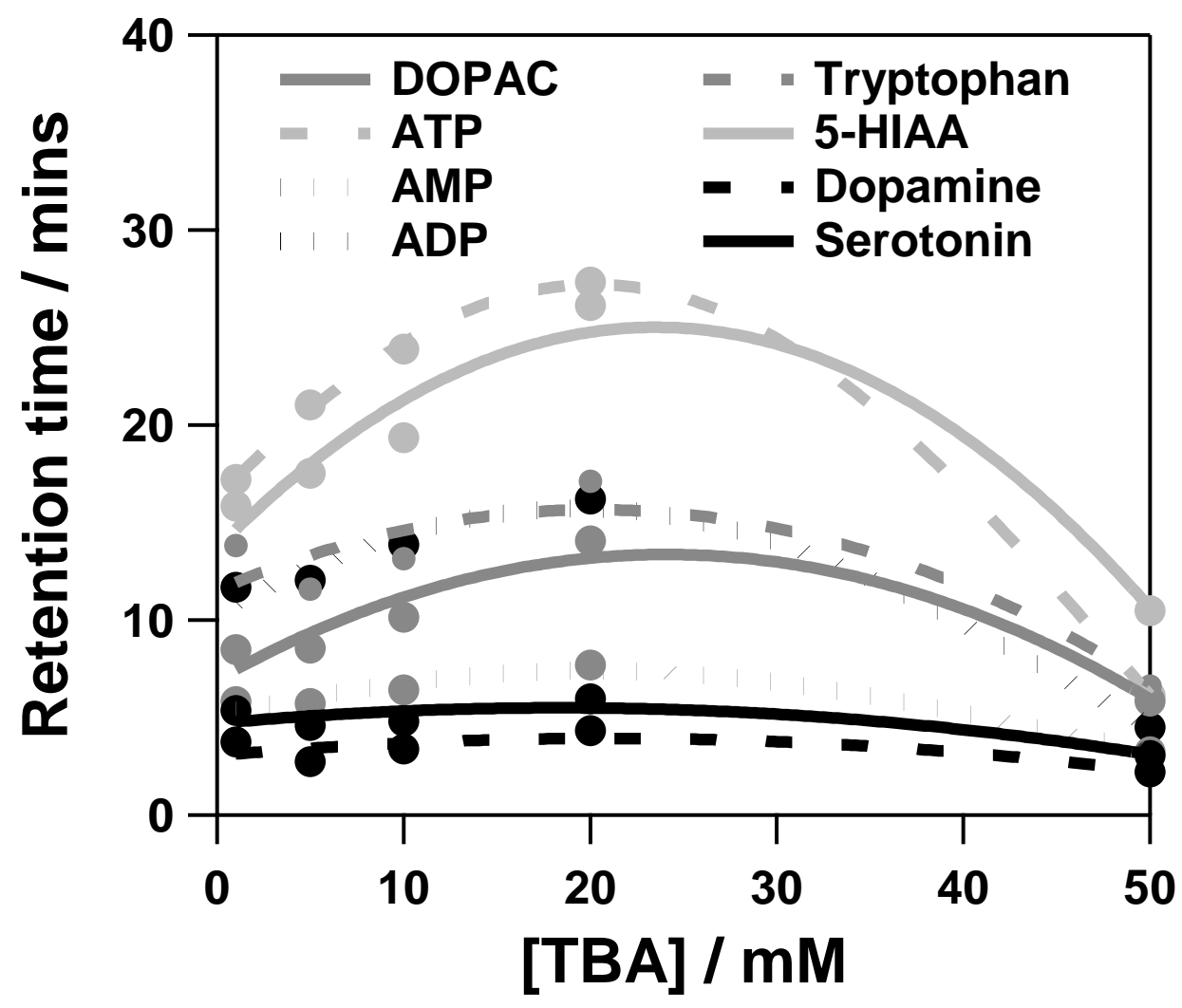


FIGURE 3
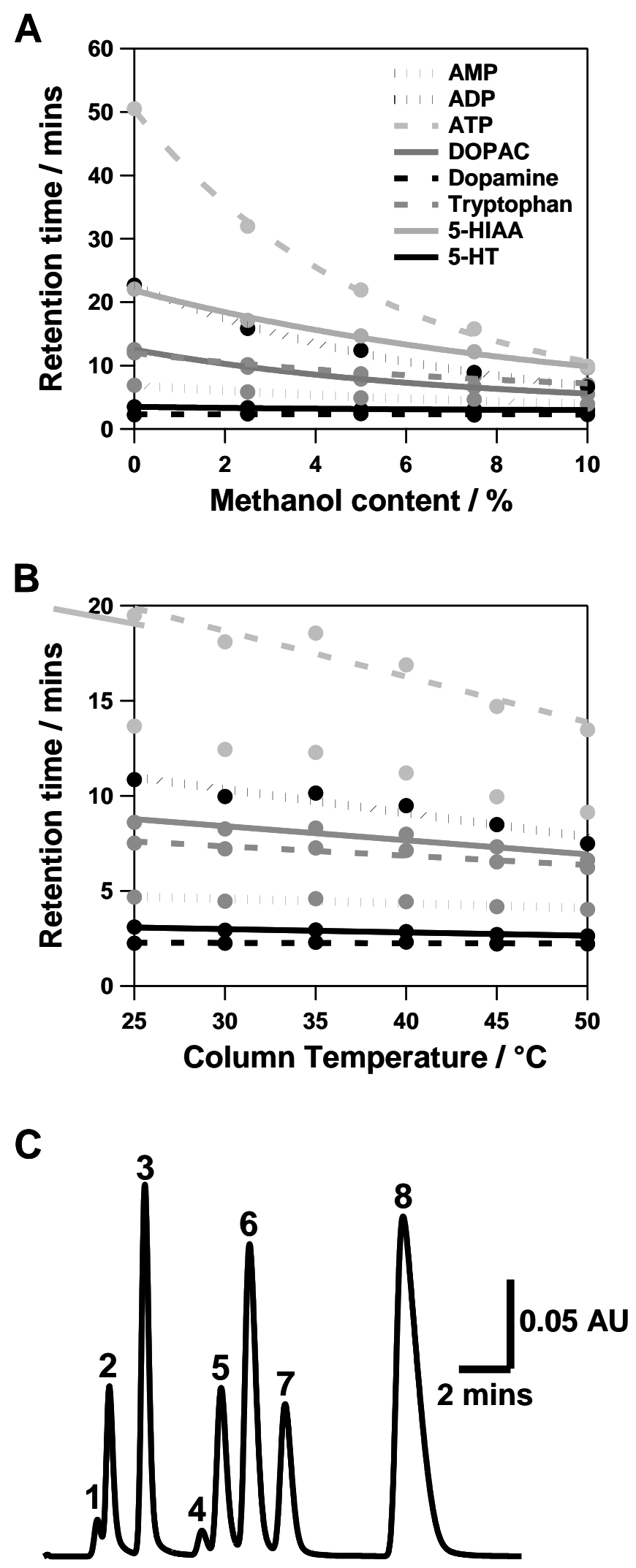
FIGURE 4
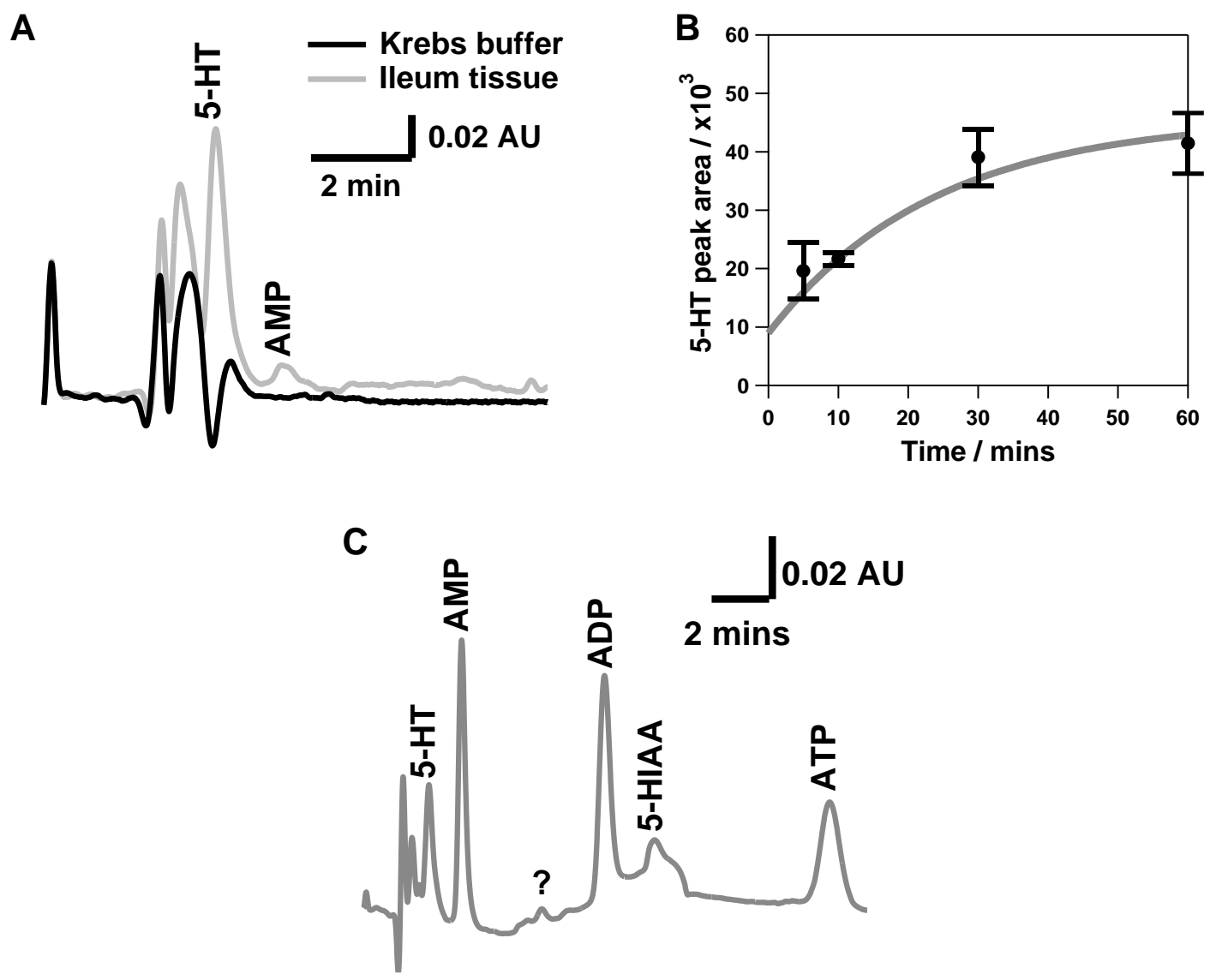
FIGURE 5
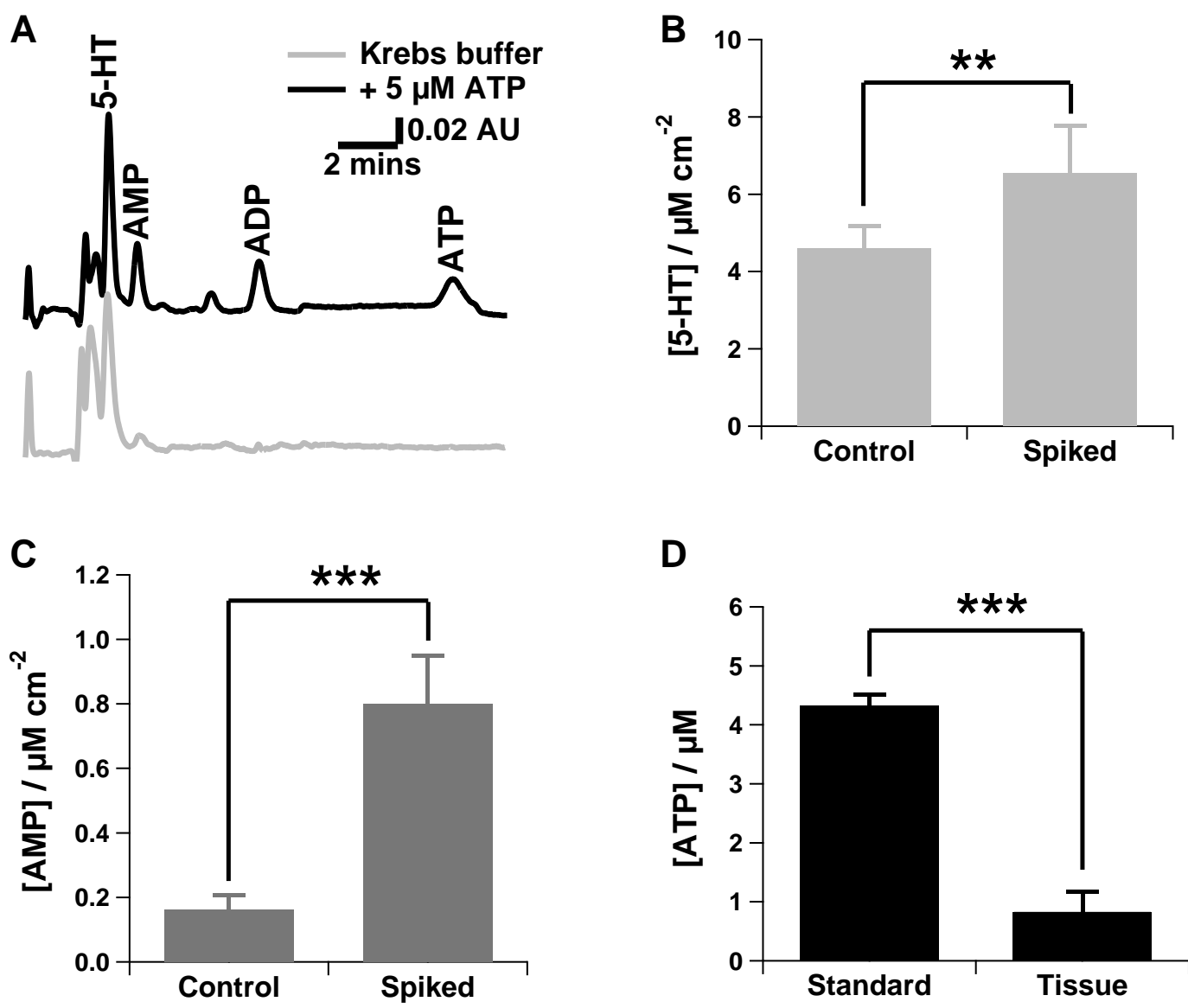
TABLE 1

\begin{tabular}{|c|c|c|c|}
\hline Standard & $\begin{array}{c}\text { Calibration range } \\
(\boldsymbol{\mu M})\end{array}$ & $\boldsymbol{R 2}$ & $\begin{array}{c}\text { Limit of detection } \\
(\boldsymbol{\mu M})\end{array}$ \\
\hline \multirow{2}{*}{ 5-HIAA } & $10-0.02$ & 0.9985 & 0.365 \\
\cline { 2 - 4 } & $1-0.02$ & 0.9945 & 0.085 \\
\hline \multirow{2}{*}{ Tryptophan } & $10-0.02$ & 0.9984 & 0.376 \\
\cline { 2 - 4 } & $1-0.02$ & 0.9948 & 0.082 \\
\hline \multirow{2}{*}{ Serotonin } & $20-0.25$ & 1.00 & 0.334 \\
\cline { 2 - 4 } & $5-0.25$ & 1.00 & 0.317 \\
\hline \multirow{2}{*}{ AMP } & $10-0.02$ & 1.00 & 0.059 \\
\cline { 2 - 4 } & $1-0.02$ & 1.00 & 0.040 \\
\hline \multirow{2}{*}{ ADP } & $10-0.02$ & 1.00 & 0.052 \\
\cline { 2 - 4 } & $1-0.02$ & 1.00 & 0.023 \\
\hline \multirow{2}{*}{ ATP } & $20-0.05$ & 1.00 & 0.085 \\
\cline { 2 - 4 } & $1-0.05$ & 1.00 & 0.030 \\
\hline \multirow{2}{*}{ Dopamine } & $10-0.1$ & 0.9991 & 0.339 \\
\cline { 2 - 4 } & $1-0.1$ & 0.9765 & 0.172 \\
\hline \multirow{2}{*}{ DOPAC } & $10-0.1$ & 0.9972 & 0.584 \\
\cline { 2 - 4 } & $1-0.1$ & 0.9797 & 0.182 \\
\hline
\end{tabular}

